\title{
Heterozygosity for Tay-Sachs disease in non- Jewish Americans with ancestry from Ireland or Great Britain
}

\author{
Margaret van Bael, Marvin R Natowicz, Jerzy Tomczak, Eugene E Grebner, \\ Elizabeth $M$ Prence
}

\begin{abstract}
We performed a genetic epidemiological analysis of American non-Jewish people with ancestry from Ireland or Great Britain with regard to heterozygosity for TaySachs disease (TSD). This study was prompted by a recent report that the frequency of heterozygosity for TSD among Irish Americans was 1 in 8 , a frequency much higher than that recognised for any other population group. We identified 19 of $576(3.3 \%)$ people of Irish background as TSD heterozygotes by the standard thermolability assay for $\beta$-hexosaminidase A (Hex A) activity. Three of 289 people of non-Irish British Isles background (1\%) were also identified as heterozygotes by biochemical testing. Specimens from the biochemically identified Irish heterozygotes were analysed for seven different Hex A $\alpha$ subunit gene mutations; three (15.8\%) had a lethal +1 IVS-9 G to $A$ mutation, previously noted to be a common mutation among TSD heterozygotes of Irish ancestry. Eight of $19(42.1 \%)$ had one of two benign or pseudodeficiency mutations, and no mutation was found in $42.1 \%$ of the heterozygotes analysed. These data indicate that non-Jewish Americans with Irish background have a significantly increased frequency of heterozygosity at the Hex $A \alpha$ subunit gene locus, but that approximately $42 \%$ of the biochemically ascertained heterozygotes have clinically benign mutations. A pseudodeficiency mutation was identified in one of the three TSD heterozygotes of non-Irish British Isles background; no mutations were found in the other two. The data allow for a frequency estimate of deleterious alleles for TSD among Irish Americans of 1 in 192 to 1 in 52. Non-Jewish Americans with ancestry from Great Britain have a minimal, if any, increase in rate of heterozygosity at the TSD gene locus relative to the general population.
\end{abstract}

(f Med Genet 1996;33:829-832)

Key words: Tay-Sachs disease; hexosaminidase; lysosomal enzyme; genetic screening.

Tay-Sachs disease (TSD) is an autosomal recessive lysosomal storage disorder caused by mutations in the $\alpha$ subunit gene of the lysosomal enzyme $\beta$-hexosaminidase A ( $\mathrm{Hex} A)$ that result in deficient activity of this hydrolase. ${ }^{12}$ This, in turn, causes an intralysosomal accumulation of $\mathrm{G}_{\mathrm{M}_{2}}$ ganglioside and the cellular and organ pathology observed in TSD. Over the past two decades, multiple clinical forms of TSD have been described that are caused by differing amounts of residual $\beta$-hexosaminidase $A$ activity in vivo. A large number of abnormal alleles resulting in pathological reductions in enzyme activity have been identified. $^{1}$

The definitive diagnosis of TSD is usually made by the demonstration of markedly reduced or deficient Hex A activity in serum or leucocytes or both using an artificial fluorescent substrate. Heterozygote status is most commonly determined by measuring Hex A activity in the same tissues; carriers have reduced Hex A activity in serum and leucocytes. ${ }^{2}$

The estimated heterozygote frequency in the general population, based on the incidence of TSD, is about 1 in 300, whereas the estimated heterozygote frequency in the general population, based on prospective biochemical testing, is about 1 in $170 . .^{12}$ The difference in these estimates is probably because of the presence of several pseudodeficiency alleles that are detected by biochemical tests but are clinically benign. ${ }^{1-5}$

The frequency of heterozygosity for TSD in several ethnic groups is considerably higher than that of the general population. Persons of Ashkenazi Jewish ethnicity have a heterozygote frequency of approximately 1 in $25 .{ }^{1267}$ Two mutations, a four base pair insertion in exon 11 (+ TATC 1278$)^{8}$ and a splice junction mutation at intron 12 ( +1 IVS $-12 \mathrm{G}$ to $\mathrm{C}),{ }^{9-11}$ are associated with the lethal infantile form of TSD and account for $90-95 \%$ of the deleterious alleles detected in Ashkenazi Jewish heterozygotes. ${ }^{12-15} \mathrm{~A}$ mutation in exon 7 (G805A) associated with a late onset form of $\mathrm{TSD}^{1617}$ accounts for $2-3 \%$ of Ashkenazi Jewish carriers with a deleterious mutation. ${ }^{12-15}$ About 2-3\% of Ashkenazi Jewish carriers have a pseudodeficiency mutation ${ }^{14}$ and approximately $2 \%$ of obligate heterozygotes have undefined mutations. ${ }^{12}$ People with French Canadian background from some parts of Canada and the United States also have an increased risk for heterozygosity for TSD. The heterozygote frequency for TSD in French Canadians in parts of eastern Quebec was noted to be 1 in $13^{18}$ and is principally the result of a $7.6 \mathrm{~kb}$ deletion in the $5^{\prime}$ end of the Hex A $\alpha$ subunit gene, ${ }^{19-21}$ although several other deleterious mutations have been detected in this ethnic 
group. ${ }^{21-23}$ A preliminary estimate of the heterozygote frequency for persons in New England who self-identified as Franco-American or French-Canadian was 1 in 53; this statistic was based on prospective biochemical screening and included people with known and suspected pseudodeficiency alleles, as well as deleterious alleles. ${ }^{24}$ An increased incidence of TSD has also been reported in several other ethnic groups and geographical isolates. ${ }^{1}$

The results from a recent study suggested that Irish Americans have an increased frequency of heterozygosity for TSD, indicating a carrier frequency of 1 in $8 .^{6}$ The mutational basis for these heterozygotes was not established in that study. At about the same time, another study reported a predominance of an intron 9 donor splice site mutation in the Hex A $\alpha$ subunit gene among non-Jewish TSD carriers from the British Isles, +1 IVS-9 $G$ to A, accounting for 10 of 24 unrelated mutant genes. ${ }^{25}$ This mutation was found more frequently in people of Irish, Scottish, and Welsh origin compared with English origin ${ }^{25}$ and, in general, appears to be a frequent cause of TSD in non-Jewish patients of European origin. ${ }^{2627}$ A subsequent study of 26 American non-Jewish TSD heterozygotes with ancestry from Ireland or Great Britain indicated that six had the intron 9 splice site mutation and that these people were all of Irish ancestry. ${ }^{28}$ This study did not report a carrier frequency for TSD among Irish Americans.

The frequency of heterozygosity for TSD reported for Irish Americans, 1 in 8, is far greater than that reported for any other population, and may have been affected by the small size of the study population, 76 subjects. ${ }^{6}$ The goal of the present study was to perform a genetic epidemiological analysis of a much larger cohort of American non-Jewish people with ancestry from Ireland and Great Britain for heterozygosity for TSD, and to examine the genotypes of the carriers identified.

\section{Methods}

The ethnic backgrounds of 11000 people who had been screened for Tay-Sachs disease carrier status between 20 July 1989 and 9 December 1994 by the Tay-Sachs Disease Prevention Program at the E K Shriver Center for Mental Retardation, Boston, MA, were ascertained by evaluation of patient intake forms that include questions regarding patient ethnicity and grandparental religion and country of origin. These records contained no information about the person's test results, which were maintained in a separate database. There were 865 subjects whose Tay-Sachs heterozygote status was evaluated during this period who had at least one parent or grandparent from Great Britain (England, Scotland, or Wales) or Ireland. This group was further divided into (1) people with Irish background $(n=576)$ and (2) people with ancestry from Great Britain $(n=289)$. Those with both backgrounds were classified as Irish for the purposes of this study. Those who also had Ashkenazi-Jewish, French-Canadian, or Franco-American backgrounds were excluded
Table 1 TSD heterozygote frequencies

\begin{tabular}{lcl}
\hline Origin & No of heterozygotes/total & Frequency (\%) \\
\hline Ireland & $19 / 576$ & $1 / 30(3.3)$ \\
Great Britain & $3 / 289$ & $1 / 96(1.0)$ \\
Ireland + Great & $22 / 865$ & $1 / 39(2.5)$ \\
$\quad$ Britain & $1 / 23(4.4)$ \\
\hline
\end{tabular}

from our study. People who were tested because a relative was either a TSD heterozygote or affected with TSD were excluded from our analysis to prevent bias of ascertainment.

The heterozygote testing results for these subjects were then reviewed. Standard thermolability assays of serum and leucocyte Hex activities were used to establish heterozygosity status at the HEXA locus. ${ }^{29} 30$ The diagnostic criteria for serum Hex A used to establish a diagnosis of heterozygosity and non-carrier status for TSD were: carrier, $\leq 55 \% \mathrm{Hex}$ A and non-carrier, $\geq 61 \% \mathrm{Hex} \mathrm{A}$. The diagnostic criteria for leucocyte Hex A were: carrier, $\leq 55 \%$ Hex A and non-carrier, $\geq 62 \%$ Hex A. Each case was individually evaluated on the basis of the serum Hex A\%, leucocyte Hex $\mathrm{A} \%$, and total Hex activity.

Molecular genetic analyses were carried out on specimens from enzymatically identified heterozygotes. The extraction of genomic DNA from the leucocyte pellets, the PCR based amplification of the relevant DNA sequences, the restriction enzyme digestions, and electrophoretic analyses for the following seven Hex A mutations, + TATC 1278, + 1 IVS-12 G to C, G805A, C739T, C745T, G748A, and +1 IVS-9 $G$ to $A$, were done using published procedures. ${ }^{424}$

\section{Results}

Of 576 subjects in the Irish group, 19 TSD heterozygotes were identified by biochemical testing, which corresponds to a heterozygote frequency of 1 in $30(3.3 \%)$. Of 289 subjects in the non-Irish British group, three TSD heterozygotes were identified by biochemical testing, indicating a carrier frequency of 1 in $96(1.0 \%)$. The combined frequency of heterozygosity for Tay-Sachs disease for all nonJewish people with a background from Ireland or Great Britain was 1 in $39(2.5 \%)$ (table 1). By way of comparison, of 1215 people of Ashkenazi Jewish ethnicity evaluated during the same time period, 53 TSD heterozygotes were identified, corresponding to a heterozygote frequency of 1 in $23(4.4 \%)$.

The complete biochemical and molecular genetic data regarding the 22 Tay-Sachs disease heterozygotes with ancestry from Ireland or Great Britain are presented in table 2. None of the heterozygotes had any of the three mutations commonly found among TSD heterozygotes of Ashkenazi Jewish ethnicity. Three (13.6\%) of the biochemically defined heterozygotes had the +1 IVS-9 G to A mutation. Six heterozygotes had the C739T mutation (27.2\%) and three heterozygotes had the C745T mutation (13.6\%). No mutation was identified in 10 heterozygotes (45\%) despite analysis for each of the above mentioned seven mutations. 
Table 2 Biochemical and molecular genetic analyses of TSD mutations

\begin{tabular}{|c|c|c|c|c|c|}
\hline \multirow[b]{2}{*}{ Patient } & \multirow[b]{2}{*}{ Mutation } & \multicolumn{2}{|c|}{ Serum } & \multicolumn{2}{|c|}{ Leucocytes } \\
\hline & & $\% A$ & Total act & $\% A$ & Sp act \\
\hline \multicolumn{6}{|c|}{ Irish heterozygotes } \\
\hline 1 & + 1 IVS-9 & ND & (P) & 49.0 & 1388 \\
\hline 2 & + 1 IVS-9 & 48.0 & 746 & 46.1 & 1208 \\
\hline 3 & + 1 IVS-9 & 49.3 & 873 & 43.0 & 1448 \\
\hline 4 & C739T & 49.5 & 705 & 46.6 & 1860 \\
\hline 5 & C739T & 49.5 & 827 & 53.9 & 1321 \\
\hline 6 & C739T & 50.5 & 1415 & 51.1 & 2026 \\
\hline 7 & C739T & 30.7 & $3026(\mathrm{P})$ & 42.6 & 2573 \\
\hline 8 & C739T & 42.0 & 1328 & 55.5 & 2350 \\
\hline 9 & C745T & 51.3 & 1162 & 54.3 & 1584 \\
\hline 10 & $\mathrm{C} 745 \mathrm{~T}$ & 55.2 & 1980 & 50.0 & 1768 \\
\hline 11 & $\mathrm{C} 745 \mathrm{~T}$ & 38.0 & 1429 & 50.1 & 759 \\
\hline 12 & 7 neg & 40.8 & $905(\mathrm{P})$ & 44.3 & 1804 \\
\hline 13 & $7 \mathrm{neg}$ & ND & & 53.8 & 2456 \\
\hline 14 & 7 neg & 42.5 & 2641 & 53.5 & 1917 \\
\hline 15 & $7 \mathrm{neg}$ & 43.9 & 1977 & 52.1 & 1615 \\
\hline 16 & 7 neg & 58.3 & 2597 & 51.5 & 2384 \\
\hline 17 & $7 \mathrm{neg}$ & 59.4 & 1038 & 51.2 & 1813 \\
\hline 18 & $7 \mathrm{neg}$ & 54.7 & 1108 & 51.7 & 1718 \\
\hline 19 & $7 \mathrm{neg}$ & 57.6 & 1014 & 51.7 & 1875 \\
\hline \multicolumn{6}{|c|}{ English, Scottish, or Welsh heterozygotes } \\
\hline 20 & $\mathrm{C} 739 \mathrm{~T}$ & 56.1 & 817 & 53.0 & 1766 \\
\hline 21 & $7 \mathrm{neg}$ & 45.4 & $1918(\mathrm{P})$ & 40.0 & 1241 \\
\hline 22 & 7 neg & 45.9 & $2429(\mathrm{P})$ & 52.1 & 2393 \\
\hline
\end{tabular}

$\% \mathrm{~A}, \% \beta$-hexosaminidase $\mathrm{A}$; total act, total $\beta$-hexosaminidase $\mathrm{A}$ and $\mathrm{B}$ activities in $\mathrm{nmol} / \mathrm{ml}$; $\mathrm{sp}$ act, specific activity of $\beta$-hexosaminidases $A$ and $B$ in $\mathrm{nmol} / \mathrm{mg} / \mathrm{h} ; 7 \mathrm{neg}$, negative for all seven mutations tested for as described in Methods; P, pregnant at the time of testing; ND, not determined.
The type of mutation in each sample is shown in fig 1 as a function of the percentage of Hex A activity in the leucocyte sample from that person. Samples containing the only disease associated mutation identified, +1 IVS- 9 G to A, cluster in the lower percentage Hex A region, while those in which no mutation could be identified usually had a higher percentage of $\mathrm{Hex}$ A. The samples containing benign mutations are distributed throughout the carrier region.

\section{Discussion}

Biochemical and molecular genetic epidemiological studies regarding Tay-Sachs disease have contributed enormously to our understanding of the genetics of the Hex A $\alpha$ subunit gene locus and have led to the development of highly successful population screening programmes. The latter, in turn, have led to a marked reduction in the incidence of this lethal neurodegenerative disorder in the Ashkenazi Jewish population. ${ }^{12}$ Several important epidemiological issues pertaining to this gene locus are incompletely understood, however. One of these concerns the frequency of heterozygosity at this gene locus among people with ancestry from Ireland or Great Britain. Recent work from an American group reported a frequency of heterozygosity for TSD of 1 in 8 for Americans with Irish background. ${ }^{6}$ This carrier frequency, if real, is greater than that observed in any of the known groups who are considered to be at high risk for heterozygosity for TSD, such as persons of Ashkenazi Jewish ethnicity. The possibility of such a high heterozygote frequency for a severe disorder would have important ramifications for this population group, if those conclusions were verified. The current study was prompted by that report.

Our data indicate that the frequency of heterozygosity at the Hex A locus for Irish Americans is 1 in 30 , much higher than the heterozygote frequency of the general population of 1 in 170 to 1 in $300 .^{1}$ Americans with English, Scottish, or Welsh backgrounds, in contrast, have a minimal, if any, increase in TSD heterozygote frequency. Our data also suggest that the previously reported heterozygote frequency for TSD in Irish Americans of 1 in 8 may be an overestimate. A possible explanation for the difference in heterozygote frequencies between our study and that previously reported may relate to the number of people analysed for each of the two studies; our sample size was approximately eight times larger.

An increased heterozygote frequency based on biochemical testing does not necessarily signify that the heterozygotes have clinically significant mutations. It is possible that some of the mutations detected by the biochemical assay are deleterious while others are benign polymorphisms. To evaluate this issue, we analysed each of the biochemically defined heterozygotes for seven mutations that were of known or possible importance for the study population. These include (1) the + TATC 12784 base pair insertion mutation that is the most common mutation in the Ashkenazi Jewish population, but is also occasionally noted in non-Jews; (2) the splice junction mutation +1 IVS-12 G to $C$, a lethal and common mutation found in Ashkenazi Jews; (3) a late onset mutation, G805A, found primarily among Ashkenazi-Jews; (4) the +1 IVS-9 G to A mutation, a lethal mutation previously reported to be common in heterozygotes with Irish ancestry; (5) the pseudodeficiency mutation C739T; (6) the pseudodeficiency mutation C745T; and (7) a possible pseudodeficiency mutation G748A.

Our molecular genetic analyses for the above seven mutations showed mutations in 11 of 19 (57.9\%) Irish American heterozygotes who were tested. It is possible that the remaining eight have other mutations not detected by our testing protocol. Alternatively, it is conceivable that some of the biochemically defined heterozygotes represent the very low end of the normal spectrum of Hex A activity.

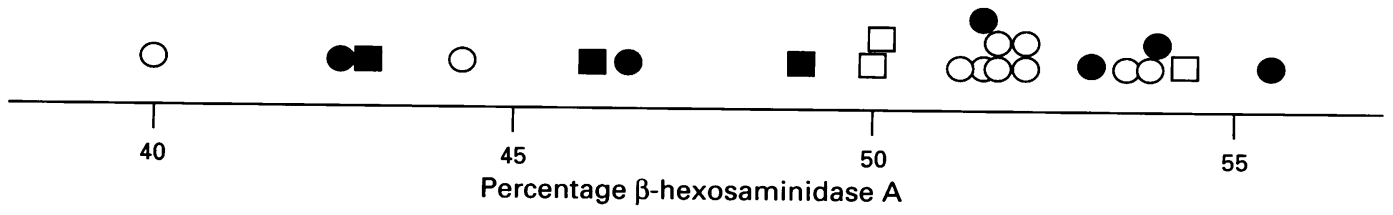

Figure 1 Correlation of mutations with level of Hex $A$ activity. Twenty-two biochemically defined TSD heterozygotes were tested for the presence of seven different Hex $A$ subunit mutations. Shown are the percentage leucocyte Hex $A$ values obtained for samples with no identifiable mutation (O), the C739T mutation (O), the C745T mutation ( $\square$ ), and the
+1 IVS-9 mutation ( $\square$ ). 
Three mutations were noted in our Irish American heterozygotes: the +1 IVS- 9 G to $\mathrm{A}, \mathrm{C} 739 \mathrm{~T}$, and C745T mutations. The +1 IVS-9 G to A or "Irish" mutation was noted in three of $19(15.8 \%)$ Irish American heterozygotes who had molecular genetic testing; this contrasts with the higher frequency $(6 / 15$ or $40 \%$ ) of that mutation noted in another study. ${ }^{28}$ This difference needs to be assessed with a still larger population set. Unexpectedly, we noted that eight of $19(42.1 \%)$ Irish American TSD heterozygotes had one of two Hex A pseudodeficiency mutations. To the best of our knowledge, there are no published data regarding the frequency of these mutations in people with ancestry from Ireland or Great Britain. In general, it appears that the frequency of Hex A pseudodeficiency genes reported here for Irish Americans, $42 \%$, is similar to the statistic reported in other studies, $38 \%$, for the percentage of non-Jewish subjects who test as heterozygotes by biochemical assays and are determined to have a pseudodeficiency mutation. $^{5}$

The purpose of this study was to assess the frequency of mutations at the Hex $\mathrm{A} \alpha$ subunit gene locus in people with ancestry from Ireland or Great Britain and to identify the molecular basis of the biochemically ascertained heterozygotes. Of the 19 heterozygotes of Irish American background identified, three had known deleterious mutations. Consequently, the minimum heterozygote frequency of deleterious mutations for this population group is 1 in 192 $(3 / 576$ or $0.5 \%)$. In so far as mutations were not identified in eight of the 19 Irish American people who had molecular genetic analyses, and it is possible that they harbour deleterious mutations, the maximum heterozygote frequency of deleterious mutations for this population group is 1 in 52 (11/576 or $1.9 \%$ ). Additional molecular genetic analyses of the specimens with unidentified mutations will be valuable in further delineating the Tay-Sachs risk statistic for this population group. In view of the markedly different clinical significance of the mutations identified in our population of Irish Americans, our data also make clear the utility of molecular genetic analyses for the Hex A mutations + 1 IVS-9 G to A, C739T, and C745T for biochemically identified TSD heterozygotes of Irish heritage in those instances when genotype identification is warranted.

The authors thank Ms Irena Zalewski for technical assistance, Ms Leslie Prence for assistance with data entry, Ms Jean Kocsis for clerical assistance, and Ms Elaine Hiller for critical readin of the manuscript.

1 Gravel RA, Clarke JTR, Kaback MM, Mahuran D, Sandhof $\mathrm{K}$, Suzuki K. The GM2 gangliosidoses. In: Scriver CR, Beaudet AL, Sly WS, Valle D, eds. The metabolic an molecular bases of in

2 Kaback M, Lim-Steele J, Dabholkar D, Brown D, Levy N, Zeiger K. Tay-Sachs disease - carrier screening, prenatal diagnosis, and the molecular era. An international perdiagnosis, and the molecular era. An international

3 Triggs-Raine BL, Mules EH, Kaback MM, et al. A pseudodeficiency allele common in non-Jewish Tay-Sachs carriers: implications for carrier screening. Am f Hum Genet 1992;51:793-801.

4 Tomczak J, Boogen C, Grebner E. Distribution of a pseudodeficiency allele among Tay-Sachs carriers. Am f Hum Genet 1993;53:537-9.
5 Cao Z, Natowicz MR, Kaback MM, et al. A second mutation associated with apparent beta-hexosaminidase A pseudodeficiency: identification and frequency estimation. $\mathrm{Am} \mathcal{F}$ Hum Genet 1993;53:1198-205.

6 Duquette D, Charrow J. Heterozygote screening for TaySachs disease (TSD) in Chicago: carrier frequency among Irish-Catholic spouses of Jews is higher than in Jews. Am f Hum Genet 1992;51:A149.

7 Landels EC, Ellis IH, Bobrow M, Fensom AH. Tay-Sachs disease heterozygote detection: use of a centrifugal analyser for automation of hexosaminidase assays with two different artificial substrates. F Med Genet 1991;28:101-9.

8 Myerowitz R Costigan FC. The major defect in AshkenaziJews with Tay-Sachs disease is an insertion in the gene for the alpha-chain of beta-hexosaminidase. $\mathcal{F}$ Biol Chem 1988;263:18567-9.

9 Arpaia E, Dumbrille-Ross A, Maler T, et al. Identification of an altered splice site in Ashkenazi Tay-Sachs disease. Nature 1988;333:85-6.

10 Myerowitz R. Splice junction mutation in some Ashkenazi Jews with Tay-Sachs disease: evidence against a single defect within this ethnic group. Proc Natl Acad Sci USA 1988;85:3955-9.

11 Ohno K, Suzuki S. A splicing defect due to an exon-intron junctional mutation results in abnormal beta-hexosaminidase alpha chain mRNAs in Ashkenazi Jewish aminidase alpha chain mRNAs in Ashkenazi Jewish mun 1988;153:463-9.

12 Triggs-Raine BL, Feigenbaum ASJ, Natowicz M, et al. Screening for carriers of Tay-Sachs disease among Ashkenazi Jews: a comparison of DNA-based and enzymebased tests. $N$ Engl f Med 1990;323:6-12.

13 Paw BH, Tieu PT, Kaback MM, Lim J, Neufeld EF. Frequency of three Hex A mutant alleles among Jewish and non-Jewish carriers identified in a Tay-Sachs screening program. Am ₹ Hum Genet 1990;47:698-705.

14 Landels EC, Ellis IH, Fensom AH, Green PM, Bobrow M. Frequency of the Tay-Sachs disease splice and insertion mutations in the UK Ashkenazi Jewish population. $f$ Med Genet 1991;28:177-80.

15 Grebner EE, Tomczak J. Distribution of three alpha-chain beta-hexosaminidase A mutations among Tay-Sachs carriers. Am f Hum Genet 1991;48:604-7.

16 Navon R, Proia RL. The mutations in Ashkenazi Jews with adult GM2 gangliosidosis, the adult form of Tay-Sachs disease Science 1989;243:1471-4.

17 Paw B, Kaback MM, Neufeld EF. Molecular basis of adultonset and chronic GM2 gangliosidoses in patients of Ashkenazi Jewish origin: substitution of serine for glycine at position 269 of the alpha-subunit of beta-hexosaminidase. Proc Natl Acad Sci USA 1989;24:13-17.

18 Andermann E, Scriver CR, Wolfe LS, Dansky L, Andermann F. Genetic variants of Tay-Sachs disease: TaySachs disease and Sandhoff's disease in French-Canadians, juvenile Tay-Sachs disease in Lebanese $\mathrm{Ca}$ nadians and a Tay-Sachs screening program in the FrenchCanadian population. In: Kaback MM, ed Tay-Sachs disease: screening and prevention. New York: Alan R Liss, 1977.

19 Myerowitz R, Hogikyan ND. Different mutations in Ashkenazi-Jewish and non-Jewish French Canadians with Taykenazi-Jewish and non-Jewish French Can
Sachs disease. Science 1986;232:1646-8.

20 Myerowitz R, Hogikyan ND. A deletion involving Alu sequences in the beta-hexosaminidase alpha-chain gene of French Canadians with Tay-Sachs disease. $\mathcal{F}$ Biol Chem 1987;262:15396-9.

21 Hechtman P, Kaplan F, Bayleran J, et al. More than one mutant allele causes infantile Tay-Sachs disease in FrenchCanadians. Am f Hum Genet 1990;47:815-22.

22 Hechtman P, Boulay B, de Braekeleer M, et al. The intron 7 donor splice site transition: a second Tay-Sachs disease 7 donor splice site transition: a second Tay-Sachs disease

23 Fernandes MJG, Kaplan F, Natowicz M, et al. A new TaySachs disease B1 allele in exon 7 in two compound heterozygotes each with a second novel mutation. Hum Mol Genet 1992;1:759-61.

24 Triggs-Raine B, Richard M, Wasel N, Prence EM, Natowicz MR. Mutational analyses of Tay-Sachs disease: studies on Tay-Sachs carriers of French Canadian background living in New England. Am $¥$ Hum Genet 1995;56:870-9.

25 Landels EC, Green PM, Ellis IH, Fensom AH, Bobrow $M$. Beta-hexosaminidase splice site mutation has a high $M$. Beta-hexosaminidase splice site mutation has a high frequency among non-Jewish Tay-Sachs disease cart
from the British Isles. $₹$ Med Genet 1992;29:563-7.

26 Akerman BR, Zielenski J, Triggs-Raine BL, et al. A mutation common in non-Jewish Tay-Sachs disease: frequency and RNA studies. Hum Mutat 1992;1:303-9.

27 Akli S, Chelly J, Kahn A, Peonaru L. A null allele frequent in non-Jewish Tay-Sachs patients. Hum Genet 1993;90: 614-20.

28 Landels EC, Green PM, Ellis IH, et al. Further investigation of the HEX A gene intron 9 donor splice site mutation frequently found in non-Jewish Tay-Sachs disease patients from the British Isles. $\mathcal{F}$ Med Genet 1993;30:479-81.

29 Natowicz MR, Prence EM, Cajolet A. Marked variation in blood beta-hexosaminidase in Gaucher disease. Clin Chim Acta 1991;203:17-22.

30 Prence lability properties of leukocyte beta-hexosaminidase: im-
plications in screening for carriers of Tay-Sachs disease. plications in screening for car $1993 ; 39: 1811-14$. 